\title{
Constructing collaborative communities of researchers in the environmental domain. A case study of interdisciplinary research between legal scholars and policy analysts
}

\author{
Silvia Bruzzone ${ }^{\mathrm{a}, *}$, Corinne Larrue ${ }^{\mathrm{b}}$, Marleen van Rijswick ${ }^{\mathrm{c}}$, Mark Wiering ${ }^{\mathrm{d}}$, Ann Crabbé \\ ${ }^{a}$ Ecole Nationale des Ponts et Chaussées (ENPC), France \\ ${ }^{\mathrm{b}}$ Ecole d'Urbanisme de Paris, Université Paris Est Créteil, France \\ c Utrecht University, The Netherlands \\ ${ }^{\mathrm{d}}$ Radboud University, The Netherlands \\ e University of Antwerp, Belgium
}

\section{A R T I C L E I N F O}

\section{Article history:}

Received 22 April 2015

Received in revised form 16 May 2016

Accepted 17 May 2016

Available online $\mathrm{xxx}$

\section{Keywords:}

Legal-policy research

Flooding

Knowledge

Community of practice

\begin{abstract}
A B S T R A C T
The article offers an analysis of the interactions between legal and policy science researchers within a European project on flood risk management using a "Policy Arrangement Approach" (PAA). While interdisciplinary research is increasingly becoming a 'must' in environmental governance, under what conditions is cooperation possible and desirable? Our analysis shows that the PAA is not mobilized as an interdisciplinary method, but offers a framework for researchers from different disciplines to learn to work together on a subject such as flooding, requiring interdisciplinary insights. The paper shows the steps that are progressively put in place to reach a common language and reformulate issues by benefitting from each other's view and approaches. The article concludes by drawing attention to new means of knowledge production relating to so-called "messy" or "wicked" problems, such as environmental issues. Within this framework, interdisciplinary work is not considered to be a precondition for the study, but rather the result of the research process itself. The analysis draws attention to the actual (working) conditions established to create an interdisciplinary community of flooding practices by challenging disciplinary borders.
\end{abstract}

(c) 2016 Elsevier Ltd. All rights reserved.

\section{Introduction ${ }^{1}$}

The relationship between legal and policy sciences emerges as being especially meaningful in new and complex policy domains such as environmental policy, where cooperation between legal scholars and policy scientists is fundamental (Hegger et al., 2014). Moreover, interdisciplinarity is a passage obligé for the principal funding institutions at both a European and national level (Bruce et al., 2004). Nonetheless, important epistemological differences especially in the approach to knowledge and knowledge production - may be a hindrance to interdisciplinary research (Luhmann, 1983, 1987; King and Thornhill, 2003).

\footnotetext{
* Corresponding author.

E-mail address: Silvia.bruzzone@enpc.fr (S. Bruzzone).

1 We wish to thank all STAR-FLOOD researchers for their contribution to this paper: their experiences have represented fundamental data resources for our analysis.
}

Whereas in the case of policy sciences and social sciences in the broad sense methodological choices represent the core of any analysis and inform what epistemological posture the analysis will be built on, most legal practice seems to assume that methodological positions are implicit, and the focus is much more on sound analytical and logic argumentation based on data that are freely available to everyone. The specific role of the literature in the construction of legal thought, research and practice must also be mentioned in this regard. In the past in fact, law was viewed as characterized by a certain degree of intellectual impenetrability: legal methods, conceptualizations, theory and practice were considered sharing an internal coherence (Riesman, 1962; Aubert, 1963; Campbell, 1974) which represented a burden towards external cooperation and acknowledgment. In reaction to those critics, legal scholars show a more complete picture of legal research, the scope of which is much broader. It encompasses not only existing law (legislation and case law) as its field of research and its theoretical and philosophical underpinnings but also studies how law comes about (which is more than the study of 
policy alone) and what the impact is of law on social interaction (and vice versa) (Quist, 2014; D’Amato, 1984; Sugerman, 1986; Luhmann, 1988, 1993; Brouwer, 2000). The latter is the field of empirical legal research, including the sociology of law, the psychology of law and the economic analysis of law. Indeed, law is not exclusively studied in isolation without regard of its intellectual and social context and is much keener on multidisciplinary research. ${ }^{2}$

Indeed, although some authors have recently written about new disciplinary convergences between legal and policy research at an empirical level (Raynaud, 2009; Van Hoecke, 2011; Hutchinson and Duncan, 2012), cooperation may still prove difficult. Accordingly, while interdisciplinary research is increasingly becoming a 'must' at the European and national levels, under what conditions is cooperation possible and desirable?

In order to answer this question, we take flood risk management as an example to illustrate our argument. Because of the increasing numbers of flood events, the issue is important for all levels of government, and requires a rather innovative policy approach that lies at the crossroads of different policy domains such as spatial planning, water management, engineering, ecology and civil protection.

We will use the research work carried out in the context of the STAR-FLOOD project. ${ }^{3}$ This project, gathering legal researchers and policy scientists, aims to evaluate national flood risk policies and provide design principles for the improvement of flood risk governance arrangements in six European countries.

In order to achieve this purpose, the research team used an adapted version of the so-called "Policy Arrangements Approach" (PAA) (Van Tatenhove et al., 2000). Although this approach was not originally designed for interdisciplinary purposes, STAR-FLOOD mobilized and adapted the PAA dispositive to build an interdisciplinary research framework at the interface between policy and legal analysis. To what extent can the PAA be considered to be an interdisciplinary approach? What can the STAR-FLOOD experience teach us about interdisciplinary research on environmental policies especially between law and policy researchers?

The article is organized as follows. After the section on methods, we describe how the PAA has been mobilized within STAR-FLOOD to develop a common research programme and interest. The third part provides details of the practices implemented by the STARFLOOD researchers. The final part draws some preliminary conclusions stemming from this experience, and provides insights into the way collaborative and interdisciplinary research on environmental policies can be carried out.

\section{Methods}

This study is based on an analysis of the interactions between legal and policy researchers in the implementation processes of the STAR-FLOOD project.

It was immediately apparent that the work done on the development of the assessment framework of the STAR-FLOOD project (Work Package 2: Larrue et al., 2013) would be an interesting process deserving specific attention. Therefore for this Work Package 2 a newly-recruited researcher, a sociologist and leading author of this paper has been appointed. The "external" view proposed by the newcomer turned out to be critical for shining a reflective light on the research work undertaken in STARFLOOD up to that time. In order to do this, she undertook two types of work: firstly, a reconstruction of the process of adjustments of

\footnotetext{
${ }^{2}$ We would like to thank Anoeska Buijze and Bald de Vries for their clarification on the scope and diversified contribution of contemporary legal research. 3 wwW.STARFLOOD.eu.
}

the PAA to fit both legal and policy analysis in the development of STAR-FLOOD's theoretical framework and research programme; and secondly, observation of the daily practices of the researchers in both disciplines when implementing the project.

The data used in this analysis are mainly the result of:

1) interviews conducted by the newcomer with previouslyinvolved STAR-FLOOD researchers, both senior and junior;

2) the newcomer's role as a participating observer of the STARFLOOD project as a member of a national team attending the regular meetings organized with all the research partners;

3) Three questionnaires sent to all STAR-FLOOD researchers to encourage researchers to provide their experiences within the STAR-FLOOD project.

In particular, the first questionnaire focused on the preparation of the assessment framework in general, and was intended to acknowledge the difficulties encountered by researchers in implementing the project. The last two were developed specially for this article: the first one was more generally focused on understanding interdisciplinary research within STAR-FLOOD, while the second had the specific intention of clarifying certain practical aspects of their day-to-day work: how social and legal scholars work together, how they organize their fieldwork, etc. ${ }^{4}$

Last but not least, this contribution is also the result of the intense and lively discussions among its co-authors on the "STARFLOOD research methods".

One final methodological note is appropriate here: although STAR-FLOOD is an international research programme, the international "variable" has been omitted from this analysis. This means that when we refer to "legal" and "policy" researchers, we do not mention their nationality. Although the topic is a highly interesting one, we decided not to integrate it into this analysis, thereby avoiding having to open the "Pandora's box" of the development of specific disciplines and academic cultures within each country.

\section{Framing PAA categories within STAR-FLOOD: burdens and potential}

As a theoretical framework, the PAA (Van Tatenhove et al., 2000), is the result of discussions within the Political Sciences of the Environment group (Milieu en Beleid) at Radboud University, Nijmegen at the end of the 1990s. This group studied the dynamics of environmental policy at a national and European level. The PAA therefore focuses explicitly on the dynamics of policy arrangements. A policy arrangement has been defined as the 'temporary stabilization of the content and organisation of a policy domain' (Van Tatenhove et al., 2000). It is structured in four dimensions: actors, resources, rules of the game - meaning formal institutionalized rules and informal rules - and the policy-relevant discourses that determine the character of the policy arrangement (see Table 1). The central idea of this institutional approach is that it becomes possible to characterize policy domains and provide detailed information on stabilization of or changes to these dimensions, and therefore to the features of policy domains. It is therefore suitable to analyse and assess policy arrangements in the framework of the STAR-FLOOD project which aims to develop improved policy design principles for flood risk governance

The marriage between the PAA and STAR-FLOOD then continued as a Dutch story. The idea of building an interdisciplinary

\footnotetext{
${ }^{4}$ We received eight answers to the first questionnaire (five young researchers who mostly answered jointly as national team - and three senior researchers) and five answers (four young researchers and one senior researcher; three joint answers and two individual ones) to the second.
} 
Table 1

Operationalization of the Policy Arrangement Approach (PAA). (Based upon Wiering and Arts, 2006).

\begin{tabular}{|c|c|c|c|}
\hline Concept & Aspects & Dimensions & Change indicators \\
\hline Policy arrangement & Substantial & $\begin{array}{l}\text { Discourses } \\
\text { Rules }^{\mathrm{a}}\end{array}$ & $\begin{array}{l}\text { Change in: } \\
\text { *Paradigms } \\
\text { *Utopias } \\
\quad \text { *Policy programs } \\
\quad \text { *Legislation }\end{array}$ \\
\hline & Procedural & $\begin{array}{l}\text { Actors } \\
\text { Resources }\end{array}$ & $\begin{array}{l}\text { *Procedures } \\
\text { *Political culture } \\
\text { *Actor constellation } \\
\text { *Interaction patterns } \\
{ }^{*} \text { Coalitions \& oppositions } \\
{ }^{*} \text { Resource constellation } \\
\text { *Power relations } \\
\text { *Political influence }\end{array}$ \\
\hline
\end{tabular}

The rules can be both substantive and procedural in nature. The dotted line in the table marks the crossover point from substance to procedure.

project on flood risk governance bringing together social scientists and lawyers was developed in the context of a previouslyestablished collaborative relationship among researchers from the two disciplines at Utrecht University being environmental governance (Copernicus Institute) and law (Utrecht Centre for Water, Oceans and Sustainability Law) and between the policy analysts at Radboud University in Nijmegen. As the categories of the PAA refer to commonly-used terms - in particular "rules of the game", "actors" and "resources" - it seemed to be an appropriate tool for interdisciplinary research on flood risk management. Accordingly, although the PAA framework had its roots in policy analysis, its potential for integrating a legal perspective into an international comparative perspective was recognized by the promoters of the STAR-FLOOD project from the outset (see Table 2)

"the PAA explicitly offers room for legal research questions because from a legal point of view, the law includes the attribution of power and policy instruments, and also the power to obtain (financial) resources, for example by providing for a tax system. This works very well to place all relevant powers, rules and resources centre stage. Even discourses can be found in the parliamentary proceedings and legal literature that accompany proposed legislation" (Senior legal researcher)

As shown in Table 2, the two disciplines share a common sphere, in particular with regard to the substantial portion. Nonetheless, it could be said that while they share an interest in the same dimensions, they do not approach them in the same way and with the same questions. Some important differences are to be found with regard to "actors" and "rules of the game". In relation to actors, while policy scientists may be interested in researching all types of actors and actor coalitions and their formal and informal interdependencies, legal scholars focus more on the legal authority, the possibilities and powers of actors and coalitions and their formal mechanisms of participation, coordination and supervision. Important differences may then be found in how the "rules of the game" are understood. Policy scientists may look at the rules as a formalisation of values, power relations and organizational procedures. For legal scholars, the focus on policy content (divisions of responsibilities, instruments in force, etc.) represents a way of analysing the rules governing a particular policy system. Generally speaking, therefore, legal analysis tends to focus on the institutional organisation and legality and legitimacy of legal rules as well as the way these rules are used in practice, while for policy analysts, institutionalisation is a major focus, including informal rules.

\section{Implementation of the PAA by legal and policy researchers}

In this section, we discuss how the PAA was mobilized and adapted within the STAR-FLOOD project and how this analytical framework was used in practice by the researchers. As we will see,

Table 2

PAA adjusted to policy analysis and legal analysis.

\begin{tabular}{|c|c|c|}
\hline Policy analysis & DISCOURSES & Legal analysis \\
\hline How do actors/scholars see reality? & *Paradigms & $\begin{array}{l}\text { How do actors/scholars see reality (Law in the } \\
\text { Books versus Law in action); Doctrines }\end{array}$ \\
\hline values and goals at stake & *Utopias & $\begin{array}{l}\text { Values and goals at stake, implicit or explicit in } \\
\text { legal documents }\end{array}$ \\
\hline $\begin{array}{l}\text { content of policy programs, policy } \\
\text { concepts etc. }\end{array}$ & *Policy programs & $\begin{array}{l}\text { Formalisation of policy programs/content and } \\
\text { changeability of programs }\end{array}$ \\
\hline $\begin{array}{l}\text { Have discursive and organizational } \\
\text { structures been implemented and how } \\
\text { do they function? Are they also } \\
\text { formalised in law? }\end{array}$ & $\begin{array}{l}\text { RULES OF THE GAME } \\
\text { *Legislation }\end{array}$ & $\begin{array}{l}\text { What legal instruments are available for active } \\
\text { and passive management? Are there legal } \\
\text { standards (flood risk standards)? How is dealt } \\
\text { with property rights? What financing and } \\
\text { compensation mechanisms are in force? }\end{array}$ \\
\hline $\begin{array}{l}\text { What are the formal and informal rules of } \\
\text { the game of governance? }\end{array}$ & $\begin{array}{l}\text { *Procedures } \\
\text { *Political culture }\end{array}$ & $\begin{array}{l}\text { Formal procedures and assessments etc. } \\
\text { including rules for access to information, } \\
\text { participation and access to justice. } \\
\text { Formal rules of the game (e.g. formalisation of } \\
\text { consensus building in NL) }\end{array}$ \\
\hline $\begin{array}{l}\text { What actors are involved what are their } \\
\text { interdependencies? }\end{array}$ & $\begin{array}{l}\text { ACTORS AND COALITIONS } \\
{ }^{*} \text { Actor constellation } \\
{ }^{*} \text { Interaction patterns }\end{array}$ & $\begin{array}{l}\text { Legal authority and powers for active and passive } \\
\text { management. Coordination and supervision } \\
\text { mechanisms. } \\
\text { Participation rules and access to justice }\end{array}$ \\
\hline What coalitions are there to be found? & Coalitions \& oppositions & $\begin{array}{l}\text { Legal authority of specific actor coalition, legal } \\
\text { dimensions of (financial) instruments, } \\
\text { Coordination and supervision mechanisms } \\
\text { e.g. advisory committees (including experts) }\end{array}$ \\
\hline $\begin{array}{l}\text { Financial, relational. } \\
\text { Who pays who in knowledge institutes; } \\
\text { counter expertise; epistemic } \\
\text { communities sharing knowledge etc. }\end{array}$ & $\begin{array}{l}\text { RESOURCES } \\
{ }^{*} \text { Resource constellation } \\
\text { *Power relations } \\
\text { *Political influence }\end{array}$ & $\begin{array}{l}\text { Budgets for research and knowledge building } \\
\text { ensured in legislation? }\end{array}$ \\
\hline $\begin{array}{l}\text { Other resources e.g. mobilisation of } \\
\text { support within society. }\end{array}$ & & \\
\hline
\end{tabular}


not only using the PAA but also other factors contributed to a challenging cooperation between legal scholars and policy scientists.

\subsection{An adaptation of the PAA to legal thought: a matter of precision}

As stated above, from the outset it seemed feasible to use the PAA, as it offers clues for both disciplines. At the same time, the participants in the STAR-FLOOD project had extensive discussions from the earliest moments on how the PAA could be made useful for both policy scientists and legal scholars. It became clear that certain dimensions of the PAA needed to be adapted to the language and questions of legal scholars.

It was first decided that the legal scholars would formulate the questions that needed to be answered in order to conduct the legal research in the STAR-FLOOD project in addition to the social science research questions. These were integrated into the assessment framework as operational guideline questions for conducting the empirical work.

Particularly interesting is then the "negotiation" process between the lawyers and policy scientists on vocabulary. The policy analysts offered a text on the Policy Arrangements Approach in order to create an understanding of the methods; this enabled discussions to take place, and provided a start for its operationalization within STAR-FLOOD. This operationalization was then amended by the lawyers in order to achieve the greater level of precision they needed: certain terms, such as "procedures", "rules of the game" and "change", were not precise enough to cover all the legal and institutional aspects of flood risk governance.

Box 1 includes some quotations from the "Policy Arrangements Approach: conceptual starting points" prepared by the policy scientists as early input for Work Package 2 of the STAR-FLOOD project (December 2012).

The work of explication and negotiation on specific terms and their operationalization was not limited to the "rules" dimension of the PAA (Box 2).

It quickly became apparent that the creation of a glossary ( 58 pages) was desirable to provide definitions and descriptions of the concepts used in the project. The aim of the glossary was to provide an overview of possible interpretations of concepts: researchers were encouraged to think about the precise meaning of the concepts they used, and were asked to make their interpretations explicit in their texts.

"One of the noticeable differences is that in legal writing, words have very specific meanings, and there are clear rules about when and when not to apply them. In contrast, the language of social science is far more diverse and context-based - this works insofar as social science has embraced the idea of different epistemological positions, meaning we can still understand one another and accept that the same word can mean different things from different perspectives. This is something that is less obvious within legal studies" (Young legal researcher)

Beyond the different understandings of terms, one may account for the different use of certain legal dispositives between legal scholars and social scientists:

"For example, the use of circulars or administrative doctrines (the Rhône doctrine) is meaningful, as non-lawyers use them every day in their analysis, while in legal terms, the two sources are if not insignificant, at least of secondary importance. Once a problem is posed in terms of a circular, lawyers seize it and restate it in relation to the hierarchy of norms and legal force, allowing them 1) to treat the problem legally, 2) to realize the true importance of a priori non-legal tools (which are the real rules of the game), and 3) to provide non-lawyers, in turn, with critical analysis." (Young legal researcher)
In this paragraph, we have seen the adjustments that were made in order to better integrate the legal scholars' research questions and vocabulary. In particular, it is worth noting the increased level of precision contributed by the legal researchers in the definition of the research objectives, and especially in the understanding of specific terms, such as rules, competences and legitimacy.

\subsection{Beyond the PAA: discrepancies in methods}

Despite the adjustments we have seen so far in the preparation of the first deliverables, ${ }^{5}$ discrepancies became evident between the lawyers and social scientists, especially in terms of methods.

'What we discovered is that social scientists have a far more mature and well-developed methodological approach, and distinguish every separate step of their research, while lawyers, for example, will never just describe what is in the law (in which case you could just copy and paste the text of the law into your research), but immediately analyse and explain it and complement it with opinions from the case law, literature and so on. The way we describe legislation and the law often includes historical background and the way the law and the main concepts in it have been evaluated and have taken on their meaning they have nowadays.' (Law Professor)

In contrast to the policy scientists' culture of starting out with predetermined ideas on potential explanations and deductive posture, the legal scholars were much more comfortable with an inductive approach. In the preliminary phase of the actual research, there was a great deal of debate on the use of analytical frameworks to explain stability and dynamics in flood management arrangements. The policy scientists came up with an elaborate description of explanatory factors derived - among others - from the multiple streams framework (Zahariadis, 2007), the punctuated equilibrium framework (True et al., 2007) and the advocacy coalition framework (Sabatier and Weible, 2007). The lawyers were somewhat confused by this approach. First of all, these theories were not familiar to the lawyers in the research group. As noted in the minutes of the Paris meeting (2 July 2013):

"The legal scholars, once confronted with the field, will be more comfortable with trying to explain what they have experienced, and explanatory factors might appear more clearly".

As we have seen in the previous paragraphs, legal researchers tend to bring more precision to their analyses, especially in areas such as rules and lawfulness. On the contrary, social scientists tend to zoom out in order to establish broader connections among the different levels of the analysis (institutional and informal, political and discourse, institutional and at the level of civil society, etc.). While the law researchers started their research from the rules of the game as they include the powers of actors and the possibilities for gaining resources, the social scientists concentrated mainly on the other dimensions of the PAA and tried to make connections between the four of them.

It was soon clear that acknowledgement of these differences and the risk of creating separate disciplinary research blocks would be a hindrance to the research. The need to look for ways to converge the legal and policy science approaches became urgent. In order for the young (legal and social science) researchers to be able to 'co-produce' the national and local case study, the discrepancies between both disciplines in the practical research work needed to be dealt with. The next paragraph discusses how

\footnotetext{
${ }^{5}$ Hegger et al. (2013) (Work Package 1 on Problem Analysis) and Larrue et al. (2013) (Work Package 2 on the Assessment framework and methods for the empirical research).
} 
Box 1. What rule is about?

"A third 'entry point' into a policy arrangement is the dimension of 'rules'. Rules are the mutually-agreed formal procedures and informal routines of interaction within institutions"

Comments from the lawyer: It is in this aspect of the PAA that the legal view might be quite different or more extensive. It now looks as though the 'rules' merely involve procedural aspects. ( . . . ) For lawyers, substantive requirements are also of great importance: what norms, standards and implementation tools are used, and what is their legal status in several jurisdictions, how lawful and effective (enforceable) are they, how they can contribute towards the prevention of conflicts and how are conflicts dealt with.

"( . . . ) The ambiguous nature of rules in this context is further stressed by the fact that such 'regulatory power' is again often based on formal or informal rules".

Comment from the lawyer. I think you should define 'rules'. In the event you mean the law, it is exclusively controlled (in any case for the duration of a Cabinet).

"Entering the tetrahedron ${ }^{6}$ via the rules dimension is a suitable strategy for studying the influence of institutional change on particular policy areas".

Comment from the lawyer. Why only institutional change? We should also look at the substantive requirements and changes that can be identified (other standards, other instruments, other remedies). Besides the aspect of legal certainty, principles of proper or good governance can play a role (proportionality, subsidiarity, etc.).

Box 2. Discussion on other terms

The notion of "competences" has different meanings: for legal scholars, it is all about the formal competences an authority has, what an actor can or may do, what it is legal or illegal to do, etc., while for policy analysts, it is a question of skills, knowledge, attitudes, and being capable of doing something.

The same goes for "appropriateness": legal scholars focus on issues like legality, the rule of law, general principles of proper administration etc., while policy analysts concentrate on issues such institutional fit, accordance with decision-making procedures, dominant paradigms, working methods, etc.( . . .) Other examples of "boundary terms" in STAR-FLOOD are, for instance, "lawfulness" which has a legal, political and social meaning. (Senior researcher in Policy Science).

the distance was reduced.

\subsection{Reducing the distance}

Although at the beginning most discussions were on the adaptability of the PAA dispositive to both disciplines, it soon became apparent that a key aspect to be overcome was the creation of practical conditions to enable the young researchers (from both disciplines and all countries) to work together.

"The lawyers and policy analysts have to work together on a common ground. Some will start top-down [national level] (legal scholars), and some will start bottom-up [case study level] (policy analysts). Some milestones to compare law and policy analysis have to be agreed on. (. . . ) The legal level should be worked at a context and sub-system level as a start. The local level is also important as far as, for example, the implementation of rules and control is concerned" (Minutes of the Paris meeting, 2 July 2013).

The first idea was to create more opportunities for exchanges between social scientists and lawyers. During the Paris meeting (2 July 2013) it was decided that the younger researchers from all the consortium countries would meet at master classes and consortium meetings every three months instead of every six months, as initially scheduled. During these master classes, the younger researchers would discuss the concepts to be used and specifically defined milestones, deliberate on particular issues in the collaboration between the legal scholars and policy scientists, and receive specific training on research skills (interview techniques, discourse analysis etc.).

\footnotetext{
6 The four dimensions of the PAA are inextricably interwoven. Liefferink (2006) has proposed the image of a tetrahedron to symbolize this interconnectedness.
}

Another element was the promotion of closer collaboration in the empirical research work. In particular, the legal researchers were invited to participate in the interviews organized by the policy scientists. In most consortium countries, legal scholars accepted the invitation, and interviews were organized and conducted jointly.

In conclusion, convergence in the approach to the fieldwork was encouraged by: questioning the concept of separate roles for the two disciplines involved in the research, the creation of the conditions for intensified exchanges among researchers and collaborative empirical research work. Consequence of this approach was that far less legal research could be done than was originally planned as the project planned one year of case study research for each country.

But what was the position of the young researchers on the fieldwork? What was their experience of the PAA and the research work as a whole?

\subsection{Muddling through: young researchers on the fieldwork}

In this paragraph, we focus on the practical experience of interdisciplinary research within STAR-FLOOD. At this level, the researchers acknowledged the different roles played by each discipline in the research.

"With the case studies or country analysis it is helpful when the legal scholars take a first step by doing an overview of the relevant legislation in the case. This can be used by the social scientists to prepare for the interviews. Afterwards, we have a similar pattern to that of XX [name of a country in the project], where the results of the interviews form a framework out of which it becomes clear what should be investigated in further detail by the legal scholars" (Young legal researcher) 
Beyond the formal roles, the accounts tell of more dynamic interactions between the two disciplines: in particular, translation - of legal terms or concepts to social science and vice versa - is meant to play a central role in making the operational work among researchers viable and fluid.

Everyone's efforts to find a common language are very evident. Time is always spent on "translation" at meetings; otherwise it would be impossible to move the research forward. For example, when a question is asked by non-lawyers, it is always reformulated by the legal researchers based on their understanding of the problem, but this process also retroactively illuminates the non-lawyers' understanding of the problem." (Young legal researcher)

"We often have to discuss a great deal in order to understand how we respectively understand the issues. (...): we have to give details of our interpretations, as it is not "obvious" to the others: there are a lot of presuppositions, differences in what we are looking at, what we are looking for ... . it is taken for granted in each discipline, but we have to explain it to each other. The simple question "is the law well implemented?" can be understood differently by both 'sides'. The effectiveness of the law can be the main issue for a legal researcher, but it is only a small part of the problem for the social scientist when we wish to answer the question of implementation. (Young geography researcher)

But translation is not just meant to make interactions and work possible: It is through a process of translation and mutual interaction that a new understanding of problems may come about.

Even though the legal work may be rather guided by the social scientists, I think this is the first step in our collective dynamic. In a second phase, in return, lawyers bring facts and knowledge to the table that we hadn't necessarily foreseen and this can orientate our understanding and interpretations. As we progressively learn to see the research issues through our mutual point of view, we come to a different formulation of the questions. My interpretation of the issues at stake is not the same after comparison with the legal view (Young geography researcher).

In this section, we have provided some elements of the daily work done by young researchers in taking STAR-FLOOD forward. The need to reinforce the collaboration was mainly satisfied through the creation of more opportunities for exchanges and working together on workshops and joint interviews. Two elements are worth noting here: the acknowledgement of the division of roles between the two disciplines and the prioritization of social science methods and leadership in some countries in the research. Nonetheless, beyond their formal roles, the researchers acknowledge the extent to which the core of the work of the project is based on development of a common ground for understanding the problem and working together.

\section{Some preliminary conclusions: the PAA is not an interdisciplinary research method (and it never pretended to be one)}

In the previous chapters, we have given an account of the work of the STAR-FLOOD legal and policy researchers in mobilizing the Policy Arrangement Approach (PAA) in order to improve flood risk governance configurations. Because it mobilizes categories (actors, power, rules, and resources) that are shared by both disciplines, the PAA was adapted to be appropriate for both law and social sciences. Nonetheless, in the development of the assessment framework, this "flexibility" turned out to produce "false friends": terms such as 'rules' or 'legality' or 'legitimacy' that sounded familiar to both disciplines needed extensive clarification and have been the subject of long discussions. Specific adjustments were needed so that the lawyers could make it useful and usable in their work.

Despite this first adapting phase, more methodological differences relating to the approach of the research came up that pushed the research coordinators to find ways of reducing the distance between the two approaches. This led to the creation of more opportunities for exchanges among the young researchers: more frequent meetings, the involvement of legal researchers in interviews, etc. Nonetheless, the need to identify bridging mechanisms for improved integration and collaboration between the two disciplines mainly resulted in the legal researchers adapting more to social science methods and skipping important more overarching legal questions relating to European Union law, the role of property rights and transboundary flood risk management.

Our preliminary conclusion is that despite the adjustments that were made, the PAA - even the "STAR-FLOOD version" - remains an analytical framework that was developed by, and is mainly suited to, social science researchers. Because of its flexibility, the PAA leaves room for other disciplines, but it does not provide a common method in practice. We can say that the PAA dispositive is not about interdisciplinary methods at all; it is a policy science framework that has been adapted to include legal analysis.

In the light of these outcomes, we now return to our initial question: what are the potentials, the burdens and the conditions for interdisciplinary research between legal scholars and policy scientists? Despite our first preliminary conclusion, we claim that the experience in the STAR-FLOOD project provides valuable insights into interdisciplinary research, but it requires looking away from methods and focusing attention elsewhere.

\subsection{STAR-FLOOD research: problem-driven and not discipline- oriented}

From the beginning, the PAA was proposed as an opportunity to enable collaboration between two disciplines investigating floods risk governance in six European countries. However, the STARFLOOD starting point was less a reflection on interdisciplinary methods than it was a search for the most appropriate way of tackling the complex problem of flooding. We state that the success of the STAR-FLOOD approach is that it is more problemdriven than discipline-oriented. Accordingly, rather than comforting each discipline in its essence, it challenges it at its borders: it challenges legal research on its methods and epistemic and policy science on its capacity to reformulate institutional questions through the integration of more detailed legal aspects and their consequences for policy.

As a senior STAR-FLOOD researcher clearly states:

"It is a long time since I have seen myself as being within any particular discipline so I can't answer from a disciplinary perspective. (...) So I start from the problem and look for different insights from different disciplines, which include reframing the problem. (...) I don't think that problems come in little bottles labelled 'I'm an economic/sociological/legal problem, drink me!'. So I'm quite impatient with the disciplines, and especially any attempt by a specific discipline to own part of a problem. A discipline is useful to the extent that it provides a starting set of tools and insights, not a body of dogma and a set of chains." (Senior Researcher)

The main question is not (or not only) to what extent the questions typical for each discipline find an answer within the project, but rather to what extent each discipline is able to contribute towards framing a problem together with other disciplines and to find ways to solve the problem. In this regard, the focus in the STAR-FLOOD project is not so much the 
development of an interdisciplinary method but rather researching a topic from multiple disciplinary perspectives. But how is this objective pursued?

\subsection{Interdisciplinarity not a pre-condition, but built into the process}

We claim that the exploration of flooding as interdisciplinary research is carried out through a reinforcement of the working relationships of the STAR-FLOOD community of researchers. Rather than theoretically, convergence between the two disciplines is sought at the empirical level through practical, easilyidentifiable "moments" of the research, and in particular through:

- a continuous process of adaptation of the PAA to both disciplines through the preparation and integration of legal questions;

- discussions and negotiations on the development of a common understanding on specific terms and their use and implications;

- the creation of a common glossary and the integration of the questions posed by each discipline, thereby allowing acknowledgment and reformulation of the issues at stake;

- the accompaniment throughout the project of accurate guidelines to support the research work, taking into account the specificities of each discipline;

- the contamination of disciplinary languages, ways of setting problems, etc.;

- the reinforcement of team cohesion by intensifying meetings and the opportunities for exchanges via Skype, social networks, etc. .... and pub crawls are not the least important tool!

- the promotion of joint fieldwork and interviews

Last but not least, it should be remembered that the collaboration between legal scholars and policy scientists does not come out of the blue. It was inscribed in an already-existing collaborative and interdisciplinary context. The way the PAA has been mobilized shows that it was primarily to create a common ground for researchers of different disciplines to work together on the same object - the improvement of flood risk policies.

The story we have proposed in this paper then can be seen as the various steps in the construction of a "Community of Researchers" and knowledge on flooding. This idea is consciously inspired by the concept of "community of practice" (Lave and Wenger, 1991). It is mobilized to lay emphasis on the ways in which knowledge is created, spread and gathered in work practices and in the community which forms around these practices (Brown and Duguid, 1991; Zucchermaglio, 1996; Gherardi and Nicolini, 2004; Bruni and Gherardi, 2007; Siedlok et al., 2015). This approach draws special attention to how innovation and learning develop within communities of practitioners. The process we have recounted within STAR-FLOOD can be seen as the various steps in the learning process of how researchers from different epistemological backgrounds learn to work together from the creation of the consortium group, to the integration of each other's questions in the assessment framework, to the mutual understanding developed during the empirical work and finally to develop design principles for flood risk governance. In this process, the PAA represents the backbone around which the Community of Researchers develops.

In this regard, interdisciplinary work is acknowledged to be more an outcome of the research process than a pre-condition for it. Interdisciplinary work is the product of a learning process that takes place at different moments throughout the research (Nicolini et al., 2003). These moments are not pre-established; they are worked out during the entire research process by progressive adjustments in the way the joint work is performed. What we claim, therefore, is that while researchers are producing and reconfiguring knowledge on flooding itself, they are at the same time learning how to work together on an interdisciplinary subject.

\section{Interdisciplinary work and knowledge production in environmental policies}

We claim that the work done within STAR-FLOOD has important implications on how to carry out research on "wicked" or "messy" problems (Rittel and Webber, 1973; Horn and Weber, 2007). These are problems for which no single interpretation is provided and for which "a single discipline research had encountered a bottleneck and more than one discipline was needed to make a breakthrough" (Bruce et al., 2004). Environmental problems - including flooding - can without any doubt be counted among these. In other words, messy problems need other ways of producing knowledge, and in this regard, the STAR-FLOOD project provides some interesting inputs, which this contribution has sought to give account of.

The PAA is mobilized as a dispositive around which a community of researchers (and practice) progressively takes shape. From what we have seen, it represents a consistent and fairly flexible framework on the basis of which researchers from different disciplines are able to create a common vision on the problem at issue. This common vision is the result of joint work on the PAA itself. More than being a method, the PAA provides a common framework based on which a community of researchers learns how to work together and reconfigure their knowledge of a research topic.

As we have claimed in this contribution, knowledge on flooding is produced within an interdisciplinary learning community of researchers. Our analysis has shown the various steps of the construction of flood risk governance as a legal-political research object through the work developed by the STAR-FLOOD community of researchers. One could say that from the interactions between policy scientists and legal scholars flooding emerges as a more robust, dense and complex research subject. As we have seen, policy sciences provide vigorous lines of more abstract institutional interpretation, while the legal component provides a superior level of precision in terms of the formal functioning of the system and its implications.

STAR-FLOOD has not tackled the flood issue by applying a theoretical approach to interdisciplinary methods. This analysis has drawn attention to the fact that the reconfiguration of knowledge on flooding is approached as a progressive definition of the inter-disciplinary research practices of the researchers into this issue. As we have seen, disciplinary borders cannot be overcome by applying standardized or pre-established (interdisciplinary) solutions, but crossing borders should be treated as one of the actual goals of the research work.

Finally, we claim that the development of collaborative group of practice gathering researchers of different disciplines becomes a key element for exploring and environmental research issues. In this regard, future initiatives should pay attention to the specific work and knowledge developed within these collaborative groups and which allow the reconfiguration of the research object, from a disciplinary matter to a question of learning within a working community.

\section{References}

Aubert, V., 1963. Researches in the Sociology of Law. Am. Behav. Sci. 7, 16.

Brouwer, P.W., 2000. Kenmerken Van Recht [Characteristics of Law]. Ars Aequi Libri, Nijmegen.

Brown, J., Duguid, P., 1991. Organizational learning and communities of practice: toward a unified view of working, learning and bureaucratisation. Org. Sci. 2, $40-57$ 
Bruce, A., Lyall, C., Tait, J., Williams, R., 2004. Interdisciplinary integration in Europe: the case of the fifth framework programme. Futures 36, 457-470.

Bruni, A., Gherardi, S., 2007. Studiare Le Pratiche Lavorative. il Mulino, Bologna.

Campbell, C., 1974. Legal thought and juristic values. Br. J. Law Soc. 1, 13-30.

D'Amato, A., 1984. Jurisprudence: A Descriptive and Normative Analysis of Law. Kluwer, Deventer.

Gherardi, S., Nicolini, D., 2004. Apprendimento E Conoscenza Nelle Organizzazioni [Learning and Knowing in Organizations]. Carrocci, Rome.

Hegger, D.L.T., Green, C., Driessen, P.P.J., Bakker, M., Dieperink, C., Crabbé, A., Deketelaere, K., Delvaux, B., Suykens, C., Beyers, J.-C., Fournier, M., Larrue, C., Manson, C., Van Doorn-Hoekveld, W., van Rijswick, M., Kundzewicz, Z.W., Goytia Casermeiro, S., 2013. Flood Risk Management in Europe: Similarities and Differences Between the STAR-FLOOD Consortium Countries. STAR-FLOOD Consortium, Utrecht.

Hegger, D., Driessen, P., Dieperink, C., Wiering, M., Raadgever, T., van Rijswick, M., 2014. Assessing stability and dynamics in flood risk governance. an empirically illustrated research approach. Water Resour. Manage. 28, 4127-4142.

Horn, R.E., Weber, R.P., 2007. New Tools For Resolving Wicked Problems Mess Mapping and Resolution Mapping Processes. MacroVU ${ }^{\mathbb{R}}$.

Hutchinson, T., Duncan, N., 2012. Defining and describing what we do: doctrinal legal research. Deakin L. Rev. 17, 83.

King, M., Thornhill, C., 2003. Nicklas Luhmann's Theory of Politics and Law. Palgrave Macmillan, New York.

Larrue, C., Hegger, D., Tremorin, J.-B., 2013. Researching flood risk governance in Europe: a framework and methodology for assessing flood risk governance, (report no D2.2.1). STAR-FLOOD Consortium, Utrecht, The Netherlands.

Lave, J., Wenger, E., 1991. Situated Learning. Cambridge University Press, Cambridge, MA.

Liefferink, D., 2006. The dynamics of policy arrangements: turning round the tetrahedron. In: Arts, B., Leroy, P. (Eds.), Institutional Dynamics in Environmental Governance. Springer, Dordrecht, pp. 45-68.

Luhmann, N., 1983. Legitimation Durch Verfahren. Suhrkamp, Frankfurt am Main.

Luhmann, N., 1987. Soziologische aufklärung. Beiträge Zur Funktionalen Differenzierung Der Gesellschaft, vol. IV. Westdeutscher Verlag, Opladen.

Luhmann, N., 1988. Die Einheit des Rechtssystems [The unity of the legal system]. In: Teubner, G. (Ed.), Autopoietic Law: A New Approach to Law and Society. de Gruyter, Berlin/New York.
Luhmann, N., 1993. Das Recht Der Gesellschaft. Suhrkamp, Frankfurt am Main. Nicolini, D., Gherardi, S., Yanow (eds), D., 2003. Knowing in Organizations: A Practice-Based Approach. M.E. Sharpe, Armonk, NY.

Quist, C.L., 2014. Vier Typen Vragen - Een Landkaartje [Four Types of Questions: A Map]. Syllabus Integratievak, Alg. rechtsleer.

Raynaud, P., 2009. Le Droit Et La Science Politique. Jus Politicum (No. 2).

Riesman, D., 1962. Law and Sociology: Recruitment, Training and Partnership. In: Evan, Wm. (Ed.), Law and Sociology. Free Press of Glencoe, Beverly Hills.

Rittel H., Webber M., (1973), 'Dilemmas in a General Theory of Planning', pp. 155169, Policy Sciences, Vol. 4, Elsevier Scientific Publishing Company, Inc., Amsterdam, [Reprinted in N. Cross (ed.), Developments in Design Methodology, J. Wiley \& Sons Chichester, 1984, pp. 135-144.] http://www.uctc.net/mwebber/ Rittel+Webber+Dilemmas+General_Theory_of_Planning.pdf.

Sabatier, P., Weible, C.M., 2007. The advocacy coalition framework: innovations and clarifications. In: Sabatier, P.A. (Ed.), Theories of the Policy Process, 8217. Westview Press, Davis CA.

Siedlok, F., Hibbert, P., Sillince, J., 2015. From practice to collaborative community in interdisciplinary research contexts. Res. Policy 44, 96-107.

Sugerman, D., 1986. Legal theory, the common law mind and the making of the textbook tradition. In: Twining, W. (Ed.), Legal Theory and the Common Law. Basil Blackwell Press, New York.

True, J.L., Jones, B.D., Baumgartner, F.R., 2007. Punctuated-equilibrium theory: explaining stability and change in public policymaking. In: Sabatier, P.A. (Ed.), Theories of the Policy Process. Westview Press, Davis CA.

Methodologies of Legal Research. What Kind of Method for What Kind of Discipline? In: Van Hoecke, M. (Ed.), Hart Publishing, Oxford.

Van Tatenhove, J., Arts, B., Leroy, P. (Eds.), 2000. Political Modernisation and the Environment. The Renewal of Environmental Policy Arrangements. Kluwer Academic Publishers, Dordrecht/Boston/London.

Wiering, M.A., Arts, B.J.M., 2006. Discursive shifts in Dutch river management: $<$ xps:span class=ceCheck $>$ deep' institutional change or adaptation strategy? Hydrobiologia 565, 327-338.

Zahariadis, N., 2007. The multiple streams framework; structure, limitations, prospects. In: Sabatier, PA (Eds.), Theories of the Policy Process. Westview Press, Davis CA.

Zucchermaglio, C., 1996. Vygotskij in Azienda. La Nuova Italia Scientifica, Rome. 